\title{
In Google Spain v AEPD, Advocate General Jääskinen wrestles with 'right to be forgotten'
}

\section{Sue Gold}

Journal of Direct, Data and Digital Marketing Practice (2013) 15, 79-81. doi:10.1057/dddmp.2013.39

Topic: Data and privacy

Who: Advocate General Jääaskinen, the Spanish Data Protection Authority (AEPD), Mario Gonzalez and the Court of Justice of the EU

Where: Luxembourg

When: 25 June 2013

Law stated as at: 11 July 2013

What happened

Territorial scope of application of the Data Protection Directive
A Spanish individual, Mario Costeja Gonzalez, tried to get a newspaper to remove an article that related to auctioning of his property because of social security debts. He failed, but instead tried to prevent Google Spain from providing a link to the online version of the article when his name was searched.

The Spanish Data Protection Authority upheld the complaint against Google Spain. This case was then referred to the European Court of Justice (ECJ) in March 2012, after Google challenged the decision. It is one of 180 similar Spanish cases that are pending the court's decision, not due before the end of 2013.

The Advocate General ruled in favour of Google, saying that the right to be forgotten does not apply, and as such Google does not have to remove personal information from its search results. The Advocate General looked at three questions - the territorial application of the EU Data Protection Directive, the definition of 'data controller' in the context of search engines and the 'right to be forgotten'.

The Advocate General's statement is not legally binding and his role is to provide an impartial opinion for the ECJ to consider. Although not legally binding, in the majority of cases the judges follow his recommendations.

Article 4(1) of the Directive (the Directive) provides that the rules of a Member State apply when the processing is carried out by a data controller established in a Member State (or in a place where the Member State's national law applies) or if a controller established outside the EU makes use of equipment in the territory of the Member State for the purposes of processing.

Google argued that it was not established in Spain or making use of equipment in Spain and therefore did not fall within the scope of Spanish data protection rules. Google Spain stated that it was not involved in processing data and was merely a commercial representative of Google Inc 
The definition of 'data controller'

\section{The right to be forgotten}

\section{Why this matters}

for its advertising activities and therefore was not making use of equipment. The search engine also argued that the use of web spiders to index content does not constitute 'use of equipment' for these purposes.

The Advocate General concluded that processing of personal data is carried out 'in the context of the activities' of an 'establishment' of the controller within the meaning of Article 4 when the undertaking providing the internet search engine sets up in a Member State, for the purposes of promoting and selling advertising space on the search engine or in an office or subsidiary that orientates its activity towards the inhabitants of that State. He argued that this applied irrespective of data processing activities or the data subjects to whom they relate.

The Advocate General stated that when an internet search engine service provider, whose search engine locates information published or included on the internet by third parties, indexes it automatically, stores it temporarily and finally makes it available to internet users according to a particular order of preference, it only 'processes' personal data when that information contains personal data.

The Advocate General concluded that the internet search engine service provider cannot be considered as 'controller' of the processing of personal data (with the exception of the contents of the index of its search engine), provided that the service provider does not index or archive personal data against the instructions or requests of the publisher of the web page.

He rejected the idea that the Directive should be construed to apply to Google as a data controller when 'the object of processing consists of files containing personal data and other data in a haphazard, indiscriminate and random manner'. The Advocate General stated that 'search engine service providers are not responsible, on the basis of the Data Protection Directive, for personal data appearing on web pages they process'.

He concluded that, under current law, as Google cannot be considered a 'controller' of personal data, it has no responsibility to remove information, unless it is false, libelous or criminal.

The Advocate General concluded that the rights to erasure and blocking of data, and the right to object under existing legislation, do not give an individual the right to require a search engine service provider to remove indexing relating to that individual where the information was originally published legally on third-party web pages, even if the individual considers that it might be prejudicial to him. He concluded, therefore, that the Directive does not provide for a general right to be forgotten as the individual is not generally entitled to restrict the dissemination of personal data that he considers harmful to his interests.

The statement by the Advocate General focuses on three key but complex areas of data protection law, and his arguments in some cases move away from current interpretation, particularly in relation to determining whether an entity is acting as a data controller.

Of particular interest to marketers are the comments in relation to applicable law and the comments stating that where an entity sets up an operation in Europe just for marketing and advertising with no processing 
of personal data in that location, local law would still apply as the marketing activity is being directed at local inhabitants even if there is no local processing.

The application of European law to non-EU entities is still being debated in the proposed Data Protection Regulation, which provides that EU law will apply to an entity offering goods or services to individuals in the EU or monitoring their behaviour. In addition, the comments on the 'Right to be forgotten' are of interest and this topic is also the subject of much discussion under the proposed regulation.

The full statement can be found at: http://curia.europa.eu/juris/ document/document_print.jsf?doclang $=E N \&$ text $=\&$ pageIndex $=$ $0 \&$ part $=1 \&$ mode $=1$ st $\&$ docid $=138782 \&$ occ $=$ first $\&$ dir $=\& \mathrm{cid}=124792$

\section{ICO and CAP each publish new 'social engagement' guidance}

\section{Mark Smith}

Journal of Direct, Data and Digital Marketing Practice (2013) 15, 81-83. doi:10.1057/dddmp.2013.40

Topic: Social media

Who: Committee of Advertising Practice (CAP)/Information

Commissioner's Office (ICO)

When: June 2013

Where: United Kingdom

Law stated as at: 10 July 2013

\section{What happened \\ ICO guidance - social networking sites}

CAP and the ICO have both recently published new guidance that may be useful to marketers using social media.

The new ICO guidance, 'Social networking sites and online forums', focuses on the application of the Data Protection Act (DPA) 1998 to social networking websites and online forums. The guidance clarifies that organizations that use social networking sites and online forums must comply with the requirements of the DPA when processing personal data. This also applies to individuals if they are processing such data for nonpersonal reasons.

Whether an individual is processing data for non-personal reasons will depend on the facts, as indicated in the guidance. For example, a sole trader using social networking sites and online forums for business purposes and processing personal data in doing so would clearly be processing data for non-personal reasons. The ICO guidance provides a lot of detail on the 